\title{
Estimation of variety seeking for segmentation and targeting: An empirical analysis
}

Received (in revised form): 1st July, 2006

\author{
Amresh Kumar \\ is a PhD student at the School of Management, State University of New York at Buffalo, Buffalo, NY, USA.
}

\section{Minakshi Trivedi}

is Associate Professor of Marketing at the School of Management, State University of New York at Buffalo, Buffalo, NY, USA.

\begin{abstract}
The way in which consumers seek variety has been shown to follow certain patterns. These patterns are a function of how much variety individuals look for and how consistent they are in this search for variety. If such patterns do indeed, represent consumption characteristics, can they be used to segment individuals into clusters? Moreover, can each segment be then characterised by a demographic profile? These two issues are critically tied together. The formation of homogenous segments is of significant concern to a manager looking for effective ways to target consumers. Nevertheless, unless this segment is identifiable and accessible by a manager in a practical and implementable way, the strategy is of little practical use. These, then are the issues we address in this paper. We show that consumers can indeed be segmented broadly into general patterns based on variety-seeking behaviour, and then identified by certain characteristics allowing for a tailored targeting strategy.

Journal of Targeting, Measurement and Analysis for Marketing (2006) 15, 21-29. doi:10.1057/palgrave.jt.5750030
\end{abstract}

\section{INTRODUCTION}

An extensive amount of research now exists in the field of marketing dealing with the issue of variety seeking as an explanation for the phenomenon of nonzero order behaviour. Numerous models have been proposed, ${ }^{1-6}$ their use as a segmentation tool explored, and the impact of such variety-seeking segments on several decision variables studied. ${ }^{7-13}$ Hassan and $\mathrm{Craft}^{14}$ more recently use a combination of micro and macro variables to segment and subsequently, position across a variety of markets. This research

Correspondence: Minakshi Trivedi, School of Management, State University of New York at Buffalo, 215 Jacobs Management Center, Buffalo, NY 14260, USA

Tel: + 17166453213 ;

Fax: + 17166453261

E-mail: mtrivedi@buffalo.edu has been found to validate the use of variety seeking as an important segmentation tool resulting in segments that differ significantly in terms of response behaviour. Unfortunately, the models required by most of the methods are fairly complex, and the nature of the data requirements somewhat extensive.

These findings, if not the methodology itself, are certainly of great interest to product managers who may wish to target specific variety-seeking levels of consumers with segment-specific marketing efforts. Before this transition from theory to practice can be made, however, a link between the current theoretical existence of segments, as shown by some fairly complex modelling (often requiring detailed, individual level information), and a more tractable identification of the same, such as a demographic profile, must be provided. In other words, are 
there any means by which the underlying segments can be uncovered without using the complex modelling techniques used by most marketing researchers?

The purpose of this paper, then, is to study whether the latent variety-seeking segments found in the population using the complex modelling techniques can be first identified, and then characterised by some means that would make the process more amenable to a manager. With this in mind, we propose a pattern-based segmentation approach to identify clusters, based on the individual purchase history, and the variation between each pair of consecutive purchases. The result is that each individual's buying behaviour can be represented by a frequency shape, which can then be classified into sets. Rundle-Thiele and Bennett ${ }^{15}$ have attempted to predict future behaviours using a single brand loyalty measure for all market types assuming that the market is stable with high switching, low involvement and lesser risk. We avoid making such assumptions and instead, validate the pattern segmentation strategy by showing that the segments obtained match closely with those obtained using the more sophisticated models. As to the characterisation of the segments, the most obvious tool would be the use of demographic variables, which provide several means to physically access certain segments. For example, specific income segments may be targeted by identifying different geographic areas and classifying them on the basis of cost or types of homes.

Another way in which to characterise the different variety-seeking levels is to study consumption behaviours. For example, one may conjecture that a greater number of brands would be found in the consideration set of a variety seeker than a nonvariety seeker. Such rules of thumb provide a simple mechanism by which managers can segment consumers as opposed to collecting individual-level information.

The paper has been organised as follows. We begin by offering a conceptual background regarding the methodology behind the pattern-based segmentation technique. We then demonstrate our methodology using data collected in an experiment, by segmenting the consumers into clusters and profiling the clusters using demographic characteristics as well as consumption behaviours. In a second experiment, we segment the new data set using a more sophisticated model, as well as by using the pattern-based technique. A study of the correlation between the results of these two methods will confirm the validity of the method. Finally, we discuss the resulting managerial implications.

\section{CONCEPTUAL DEVELOPMENT}

The idea of associating variety-seeking behaviour with a shape was originally proposed by Trivedi et al., ${ }^{6}$ when they estimated an underlying distribution of variety seeking for each individual using a stochastic variety seeking (SVS) model, expressible as a sum of two hypergeometric functions. Essentially, the frequency with which various levels of variety were sought was estimated by the beta distribution that represented the individual consumer's buying patterns. The mode of the distribution represented the most frequent level of variety sought. In order to parameterise the SVS model, the data requirements included information on purchasing, as well as detailed information on perceptions of similarity between products and specific attributes that contribute to the product description (see Trivedi et al. ${ }^{6}$ for a more detailed treatment).

Essentially, then, the model used a beta distribution to emulate variety seeking, using purchasing data to parameterise the model, and once the parameters were estimated, the exact beta distribution was plotted. (This amounts, more or less, to plotting a regression line using estimated coefficients, once the equation has been estimated based on data.) Just as we can go back and actually plot a scatter diagram to show the raw relationship between dependent and independent variables estimated by the equation, we can also visually study the relationship between the variables in the SVS model. Since the graphs of beta distributions obtained are simply frequency distributions of the different levels of variety sought, and since our purpose is to segment them into general shapes (see Figure 1) as opposed to characterise each 
individual with a specific set of parameter values, it seems logical to study the scatter plots of raw data rather than the more contrived beta distribution fitted relationships. The advantage in doing so, of course, would be the ability to categorise behaviours into segments without the additional rather elaborate data requirements, or the complex modelling techniques. These segments, moreover, will speak to issues regarding switching behaviours that allow segment-specific profiling and targeting. Figure 2 shows the conceptual framework behind the two schemes discussed.

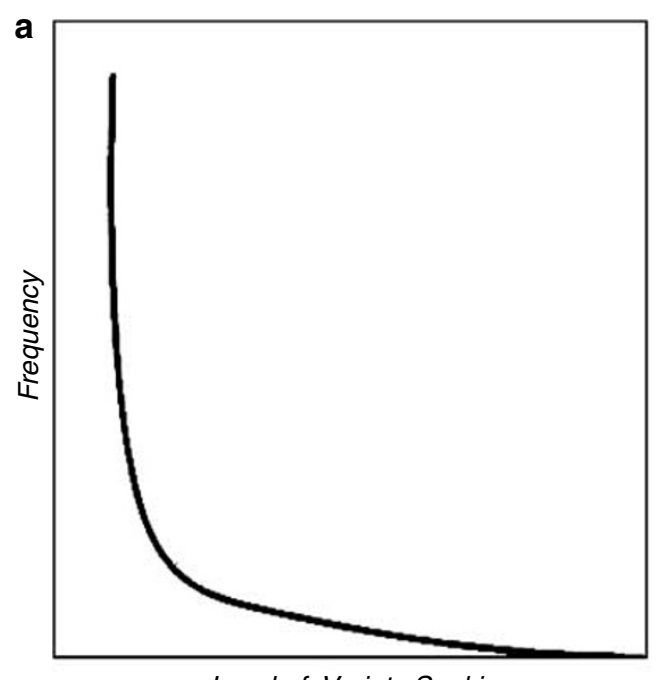

Level of Variety Seeking

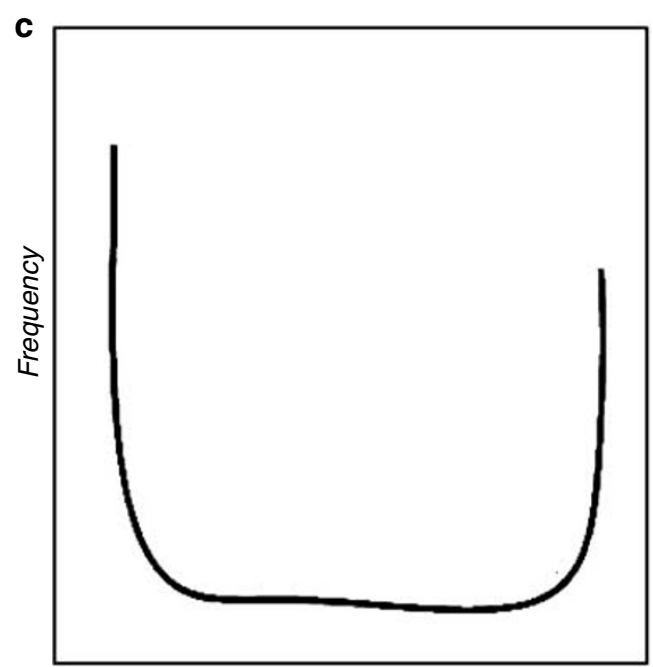

Level of Variety Seeking
EMPIRICAL STUDY 1: THE SHAPE OF VARIETY

\section{Data}

The product chosen had to be such that respondents were familiar with the brands and furthermore, had a reasonably high consumption frequency. One product category that met the requirements defined was soft drinks. Two pre-tests indicated that the selected subjects had a high familiarity with it and were frequent consumers of brands in the category. Moreover, the use of this category for prior work in this
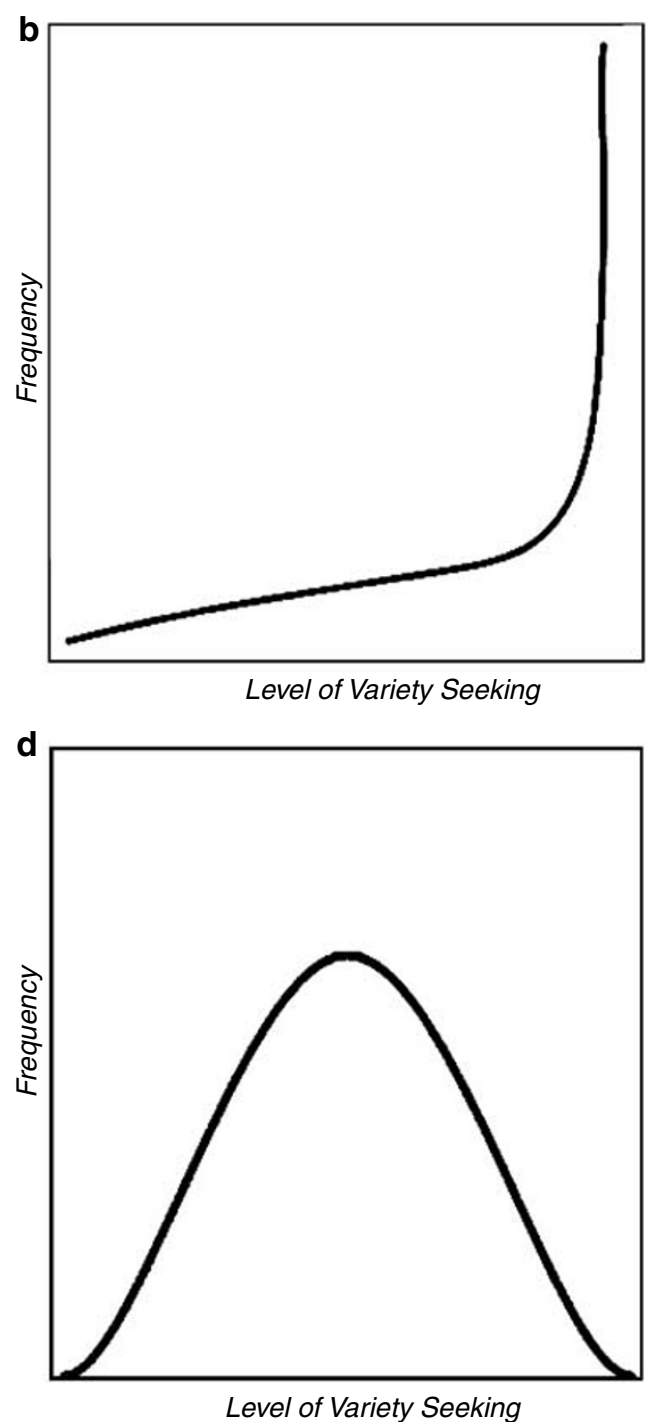

Figure 1: Different segments. (a) Brand loyal segment, (b) Pure variety-seeking segment, (c) Regular variety-seeking segment, (d) Switching segment 
area lends further support for this choice, and will provide a base line of comparison for the product category.

Subjects were recruited from a research pool at a large state university school over the spring of 1998, in exchange for extra course credit for participation. Subjects signed up in small groups (not more than ten individuals). They were motivated within these groups to respond thoughtfully and accurately. Two pre-test sessions were run to help refine experimental instructions and to ensure that subjects understood the nature of the task and were consumers of this product category. Subjects worked individually, with 90 per cent of them completing the task within $45 \mathrm{~min}$. At the end of the survey, all subjects completed a section containing demographic and lifestyle variables. One subject did not complete the survey portion on response to promotions, while another's responses did not vary over these items. Both subjects were removed producing a usable sample of 72 subjects. The mean age of the subjects was 23 years and the male to female ratio was 51:49 per cent. Test-retest reliability was found to be significant at the 0.001 level.

Each subject completed a brand purchase history of 30 hypothetical purchases of soft drinks, required for the estimation of the segmentation models. A list of 26 different brand forms (brand, caffeination, diet, flavour, etc), and one category for 'all other', was formed from the resulting purchase history data. Subjects were then asked to allocate 100 points among the brands to reflect their relative preferences.

\section{Segmentation (pattern based)}

Table 1 gives the list of brand forms and the variables used to define the products.

Using a 0-1 dummy variable for each of the attributes $\left(D_{i}\right)$, we assign a value for the similarity $\left(S_{i j}\right)$ between each pair of choices made by the individual, such that

$$
\mathrm{S}_{\mathrm{ij}}=\sum \operatorname{ABS}\left[\left(\mathrm{D}_{\mathrm{i}}-\mathrm{D}_{\mathrm{j}}\right)\right]
$$

A simple frequency distribution of the similarities $\left(S_{i j}\right)$ reveal the general pattern observed in terms
Table 1: Brand forms and variables

\begin{tabular}{lll}
\hline Brand forms & & Variables \\
\hline $\begin{array}{l}\text { Classic Coke } \\
\text { Diet Coke }\end{array}$ & New Coke & Caffeine-free Coke \\
$\begin{array}{l}\text { Caffeine-free Diet } \\
\text { Coke }\end{array}$ & Cherry Coke & $\begin{array}{l}\text { Caffeination } \\
\text { Diet/regular }\end{array}$ \\
$\begin{array}{l}\text { Diet Cherry Coke } \\
\text { Diet Dr. Pepper }\end{array}$ & Dr. Pepper & Flavour \\
Pepsi & Pepper free & \\
Pepsi free & Diet Pepsi & \\
7-UP & Diet Pepsi free & \\
Sprite & Diet 7-UP & \\
Squirt & Diet Sprite & \\
Orange Crush & Diet Squirt & \\
Mountain Dew & Sunkist Orange & \\
A \& W Root Beer & Diet Mountain Dew & \\
\hline
\end{tabular}

of the degree to which consumers seek variety between consecutive purchases. Since each individual made 30 choices, the frequency distributions consisted of 29 observations. The individuals were then segmented in accordance with the variety-seeking shapes obtained. This resulted in the following four generalisable shapes, displayed in Figure 2.

As can be seen, Figure 1(a) represents behaviour that is primarily loyal to one brand (brand loyal segment), so that the distribution peaks close to 0 , indicating that such consumers frequently repeat purchase their brands.

Figure 1(b) represents the extreme variety-seeking segment (pure variety-seeking segment), with the distribution peaking closer to one, and indicating that these consumers typically look for very different products on consecutive purchase occasions. Figure 1(c) represents the regular variety-seeking segment (variety-seeking segment), with consumers often choosing the same or similar product, but also sometimes a different product. In such a case, the distribution can be seen to be U-shaped, with one peak close to the zero level, and another one further out. Finally, Figure 1(d) represents the behaviour of consumers with no particular loyalty to any one brand, so that they often switch to different brands (switching segment). The mode of the distribution appears within the graph, the position of which indicates the degree to which different products are chosen to switch to.

Classification of each individual within each segment shape is given in Table 2. (Three 


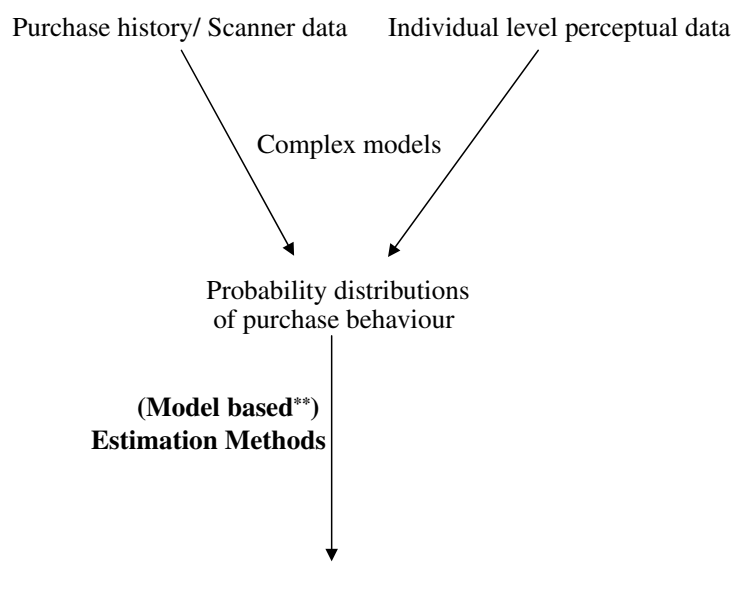

Variety Seeking/Brand Loyalty Estimates

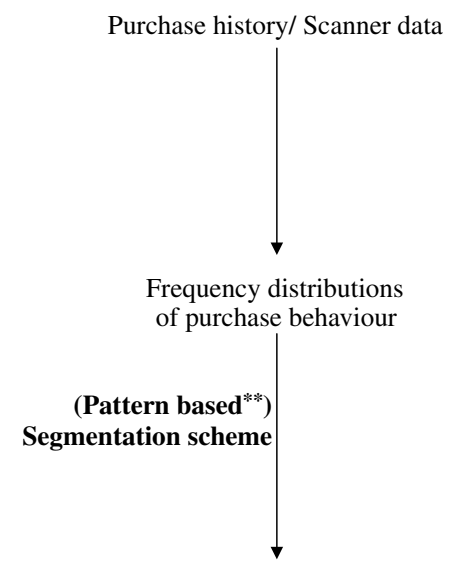

Variety Seeking/Brand Loyalty Segments

Figure 2*: Conceptual framework for model-based and pattern-based segmentation schemes.

${ }^{*}$ The authors would like to thank an anonymous reviewer for suggesting a diagrammatic framework.

${ }^{\star \star}$ Note that significant agreement was found at the broad level between the model-based and pattern-based segmentation schemes

Table 2: Segment membership

\begin{tabular}{lllr}
\hline & Segment & $\begin{array}{l}\text { No. of segment } \\
\text { members }\end{array}$ & Percentage \\
\hline 1 & Brand loyal & 16 & 23 \\
2 & Pure variety seeking & 14 & 20 \\
3 & Variety seeking & 33 & 48 \\
4 & Switching & 6 & 9 \\
& Total & 69 & 100 \\
\hline
\end{tabular}

individuals could not be classified as the distributions shapes were ambiguous.)

\section{Profile of segments}

Demographic information for consumers in each segment is averaged. Table 3 gives the demographic profile for each segment as well as the average over all the segments.

\section{Implications}

It is interesting to note that about 20 per cent of consumers in the sample fall into the pure variety-seeking segment, supporting previous results stating that a majority of consumers' behaviour could be estimated using a simple brand loyal function, with only about 15-30 per cent needing a more extreme modelling approach.

Furthermore, Table 3 shows that while not all demographics discriminate between all pairs of categories, there are certainly some aspects that differentiate between some of the segments. These are highlighted in Table 3. As can be seen, most of the consumers in the pure variety-seeking category were found to be in a relatively younger age group, with a higher quantity and frequency of consumption. As opposed to that, the varietyseeking segment, who either switch to something very similar or something very different, consume far less and over fewer occasions. Such consumers can be thought to consume soft drinks over only a couple of occasions, with a favourite soft drink for each occasion. In other words, their choice is occasion specific.

\section{EMPIRICAL STUDY 2: VALIDATION}

In order to validate the above methodology, we replicate it with data used for more sophisticated modelling approaches and compare the segmentation results. Thus, using data from the Trivedi et al. ${ }^{6}$ model, we use our simpler segmentation approach and compare the clusters obtained with those achieved from the original study.

\section{Data}

Trivedi et al. ${ }^{6}$ selected 25 individuals and three product categories (soft drinks, beer and video cassette movie rentals) for their study. Motivation to participate was in the form of free products 
Table 3: Mean demographics by segment

\begin{tabular}{lllll}
\hline & Segment & Age & $\begin{array}{l}\text { No. of consumption } \\
\text { occasions }\end{array}$ & $\begin{array}{l}\text { Frequency of consumption } \\
\text { (cans/day) }\end{array}$ \\
\hline 1 & Brand loyal & 27 & 3.2 & 4.5 \\
2 & Pure variety seeking & 20 & 3.4 & 4.2 \\
3 & Variety seeking & 23 & 1.7 & 2.1 \\
4 & Switching & 19 & 3.6 & 2.4 \\
& Average & 22.9 & & 3.1 \\
\hline
\end{tabular}

provided - this would also serve to remove price and promotion effects in purchase selection. Once screened for suitability, individuals were required to maintain consumption diaries for all three product categories. For soft drinks and beer, subjects were asked to place an order with a delivery company, with which arrangements had been made for this purpose. The brand selected was reported on the individual's card, and the product of the subject's choice delivered to him/her. Subjects were allowed to reorder as and when their stock depleted, but only a single unit at a time.

In the case of the video cassette movies, a rental store at a nearby, central location was selected. Subjects were then asked to use the same location for selection of their video movies over the next few months. Reimbursement for the rentals was made as and when receipts for the rentals were sent in.

Subjects were encouraged not to purchase these product categories from other sources.

One motivation for doing this would be that the products offered by the researchers would be free. Thus, sequential purchase data over a period of three to four months (depending on the product category) was obtained.

Finally, individual level data on similarity judgments between different brands in a category (from here on, we refer to the types of movies as brands within the category as well), attribute levels for each brand and importance ratings for each attribute, were obtained using a questionnaire for each category. Previous research as well as informal discussion with graduate management students revealed an initial set of brands and attributes to work with. For the movie category, the brands were defined by the classification used by the rental store. This initial set of attributes was then refined and expanded using direct elicitation from subjects during the
Table 4: Brands and attributes

\begin{tabular}{|c|c|c|}
\hline Category & Brands & Attributes \\
\hline Soft drinks & $\begin{array}{l}\text { Coke (7 flavours) } \\
\text { Pepsi (4 flavours) } \\
\text { Dr. Pepper (3 flavours) } \\
\text { 7-UP, Ginger Ale } \\
\text { Slice \& Sprite (2 } \\
\text { flavours each) } \\
\text { Big Red } \\
\text { Mountain Dew } \\
\text { Orange Crush } \\
\text { A \& W Root Beer } \\
\text { Shasta Cola } \\
\text { Sunkist Orange }\end{array}$ & $\begin{array}{l}\text { Thirst quenching } \\
\text { Calorie content } \\
\text { Sugar content } \\
\text { Flavour } \\
\text { Sweetness } \\
\text { Light taste } \\
\text { Syrupy } \\
\text { Sodium content } \\
\text { Caffeine content } \\
\text { Refreshing } \\
\text { Fizzy } \\
\text { Aftertaste } \\
\text { Uplifting } \\
\text { Real cola taste }\end{array}$ \\
\hline Beer & $\begin{array}{l}\text { Budweiser } \\
\text { Coors } \\
\text { Michelob/Miller } \\
\text { Corona } \\
\text { Michelob Dry } \\
\text { Miller Draft } \\
\text { Old Milwaukee } \\
\text { Olympia }\end{array}$ & $\begin{array}{l}\text { Alcohol content } \\
\text { Calorie content } \\
\text { Full bodies flavour } \\
\text { Lightness } \\
\text { Bitterness } \\
\text { Sweetness } \\
\text { Smoothness } \\
\text { Aftertaste }\end{array}$ \\
\hline Video rentals & $\begin{array}{l}\text { Action adventure } \\
\text { Comedy drama } \\
\text { Family, foreign } \\
\text { Horror, music } \\
\text { Video, musical } \\
\text { Science fiction } \\
\text { Special interest } \\
\text { Western }\end{array}$ & $\begin{array}{l}\text { Exciting } \\
\text { Uplifting } \\
\text { Relaxing } \\
\text { Sentimental } \\
\text { Can relate to it } \\
\text { Depicts real life } \\
\text { Emotional } \\
\text { Provides diversion } \\
\text { Humorous } \\
\text { Provides escape } \\
\text { from real life }\end{array}$ \\
\hline
\end{tabular}

personal interviews. The set of brands and attributes used in each category for data collection is given in Table 4. Several of the questions were repeated to ensure the reliability of the data collected.

The final data set consisted of 25 subjects in the sample. Three individuals were unable to complete the study while another two were unable to provide sufficient data because of low consumption in all the product categories. From 
the remaining 20 individuals, four did not consume beer (but were frequent consumers of the other two categories and were thus retained for the study) or did so too infrequently to provide reliable beer consumption data. In the product category of video cassette rentals, sufficient choice data could only be obtained from ten individuals. Thus, the 20 individuals in the sample yielded 20 data sets for soft drink, 16 data sets for beer and ten data sets for video cassette rentals.

Reliability tests on the attribute data collected revealed that two of the data sets in the soft drink category were unusable due to low correlations $(<0.75)$ with repeated questions. The remaining 45 individual level data sets (18 for soft drinks, 14 for beer and 13 for video cassette rentals) consisting of choice sequences and attribute data, were then used for the analysis.

For soft drinks, the number of choice occasions ranged between 81 and 348, while for beer and video cassette rentals, the number of choice occasions ranged between 87 and 292, and 89 and 188, respectively. These sequences were then used to formulate conditional probabilities, and the attribute data, to determine dissimilarity indices. The final data for analysis thus consisted of 45 sets of individual level observations on conditional probabilities, and dissimilarity indices for each pair of brands, including the ideal brand.

\section{Segmentation (pattern based and model based)}

Repeating the pattern-based method of segmentation discussed above, we obtain the classification shown in Table 5 . Four of the 45 data sets could not be classified due to ambiguity in the patterns. We also display the results from the original variety-seeking model estimation that determines the underlying process of the variety-seeking behaviour (Table 5). A summary of the cross-classification is displayed in Table 6.

\section{Implications}

As can be seen, 81 per cent ( 34 out of 42 ) of the sample is identically classified by both model-based and pattern-based comparison methods. If we look at the classification of the brand loyal segment (that is, the zero-order behaviours), this percentage of identically classified goes up to 92 per cent (13 out of 14). The percentage for the remaining segments (that is, the nonzero-order segments) is 75 per cent. Obviously, the pattern-based method identifies the brand loyal segment with greater accuracy than it does for the remaining nonzero-order segments. This is consistent with earlier results showing that the model-based methods are particularly effective in identifying nonzero-order behaviour. Note, however, that if the purpose were to simply identify nonzero-order behaviour, then the accuracy of the pattern-based method remains 92 per cent (39 out of 42).

This has very interesting implications for managers. For example, if the purpose of the segmentation is to identify those loyal to their product and have an 'other' category for the remaining individuals, the pattern-based method of segmentation provides a low cost, effective means of identifying the categories. In situations where the purpose is to reward loyalty or offer promotional incentives to the other category (which are some of the most common reasons to identify segments), the drawn out process of data collection and subsequent analysis can be avoided by simply using scanner databases available that track purchase histories. Only in cases where a more sophisticated promotional targeting practice is planned such that variety seekers, say, need to be distinguished from pure variety seekers, will model-based segmentation be a necessity.

\section{DISCUSSION}

The ability of mathematical models to segment consumers into homogeneous clusters has been repeatedly demonstrated in the literature by various researchers. Unfortunately, the data requirements for such models are often onerous and time consuming. A manager wishing to quickly implement a promotional strategy to counteract a competitor's move, for example, would be hard put to develop a questionnaire, administer it to a sample and collect and analyse the data before any strategy can be decided. 
Table 5: Individual variety-seeking segments

\begin{tabular}{|c|c|c|c|c|}
\hline Obs. No. & Subject & Category & $\begin{array}{l}\text { Model-based } \\
\text { segmentation }\end{array}$ & $\begin{array}{l}\text { Pattern-based } \\
\text { segmentation }\end{array}$ \\
\hline 1 & 1 & Soft drinks & Brand loyal & Brand loyal \\
\hline 2 & 2 & Soft drinks & Brand loyal & Brand loyal \\
\hline 3 & 2 & Beer & Variety seeking & Brand loyal $^{*}$ \\
\hline 4 & 2 & Video rentals & Variety seeking & Variety seeking \\
\hline 5 & 3 & Soft drinks & Variety seeking & Switching $^{\star}$ \\
\hline 6 & 4 & Soft drinks & Variety seeking & Brand loyal \\
\hline 7 & 5 & Soft drinks & Variety seeking & Variety seeking \\
\hline 8 & 5 & Beer & Variety seeking & ** \\
\hline 9 & 5 & Video rentals & Variety seeking & Variety seeking \\
\hline 10 & 6 & Soft drinks & Switching & Variety seeking ${ }^{*}$ \\
\hline 11 & 6 & Beer & Variety seeking & Variety seeking \\
\hline 12 & 7 & Soft drinks & Variety seeking & Variety seeking \\
\hline 13 & 7 & Beer & Brand loyal & Brand loyal \\
\hline 14 & 7 & Video rentals & Brand loyal & Brand loyal \\
\hline 15 & 8 & Soft drinks & Variety seeking & Variety seeking \\
\hline 16 & 8 & Beer & Variety seeking & Variety seeking \\
\hline 17 & 8 & Video rentals & Variety seeking & Variety seeking \\
\hline 18 & 9 & Soft drinks & Brand loyal & Brand loyal \\
\hline 19 & 9 & Beer & Variety seeking & Variety seeking \\
\hline 20 & 9 & Video rentals & Variety seeking & Variety seeking \\
\hline 21 & 10 & Soft drinks & Brand loyal & Brand loyal \\
\hline 22 & 10 & Beer & Pure variety seeking & Pure variety seeking \\
\hline 23 & 10 & Video Rentals & Pure variety seeking & Switching* \\
\hline 24 & 11 & Soft drinks & Switching & Switching \\
\hline 25 & 11 & Beer & Brand loyal & Brand loyal \\
\hline 26 & 11 & Video rentals & Variety seeking & Variety seeking \\
\hline 27 & 12 & Soft drinks & Variety seeking & Variety seeking \\
\hline 28 & 12 & Beer & Brand loyal & ** \\
\hline 29 & 13 & Soft drinks & Pure variety seeking & Variety seeking* \\
\hline 30 & 13 & Video rentals & Brand loyal & Switching* \\
\hline 31 & 14 & Soft drinks & Variety seeking & ** \\
\hline 32 & 14 & Beer & Brand loyal & Brand loyal \\
\hline 33 & 14 & Video rentals & Variety seeking & Variety seeking \\
\hline 34 & 15 & Soft drinks & Brand loyal & Brand loyal \\
\hline 35 & 15 & Beer & Brand loyal & Brand loyal \\
\hline 36 & 16 & Soft drinks & Variety seeking & $\star *$ \\
\hline 37 & 16 & Beer & Brand loyal & Brand loyal \\
\hline 38 & 16 & Video rentals & Brand loyal & Brand loyal \\
\hline 39 & 17 & Soft drinks & Pure variety seeking & Pure variety seeking \\
\hline 40 & 17 & Video rentals & Variety seeking & Variety seeking \\
\hline 41 & 18 & Soft drinks & Variety seeking & Switching ${ }^{*}$ \\
\hline 42 & 18 & Beer & Pure variety seeking & Pure variety seeking \\
\hline 43 & 18 & Video rentals & Pure variety seeking & Pure variety seeking \\
\hline 44 & 19 & Beer & Switching & Switching \\
\hline 45 & 19 & Video rentals & Pure variety seeking & Pure variety seeking \\
\hline
\end{tabular}

*Indicates different classification of individual into a segment.

${ }^{* \star}$ Indicates pattern too ambiguous to classify.

Table 6: Cross-classification by models

\begin{tabular}{lllll}
\hline $\begin{array}{l}\text { Pattern based model } \\
\text { based }\end{array}$ & Brand loyal & Variety seeking & Switching & Pure variety seeking \\
\hline Brand loyal & $13(28.89 \%)$ & $0(0 \%)$ & $1(2.22 \%)$ & $0(0 \%)$ \\
Variety seeking & $2(4.44 \%)$ & $14(31.11 \%)$ & $2(4.44 \%)$ & $0(0 \%)$ \\
Switching & $0(0 \%)$ & $1(2.22 \%)$ & $2(4.44 \%)$ & $0(0 \%)$ \\
Pure variety seeking & $0(0 \%)$ & $1(2.22 \%)$ & $1(2.22 \%)$ & $5(11.11 \%)$ \\
\hline
\end{tabular}

Informal discussions with a major retail chain in the northeast revealed that most managers wishing to target a specific segment will study a simple frequency distribution of products purchased. Then, depending on the objectives of the promotional strategy, the most purchased or the 
least purchased product may be promoted. This strategy disregards the fact that the household may or may not be susceptible to promotions and a study of the distributions of products purchased will not reveal the same. Our method of patternbased segmentation studies the order of brands purchased and switching behaviour of consumers, and is therefore more revealing of the intrinsic variety seeking or switching tendencies of consumers. While this method does require a slightly higher level of technical understanding, it is far simpler than the expertise required to apply the more complex models currently popular in much of academia.

The above results show that the pattern-based approach suggested in this paper will provide a simple but effective tool in the hands of managers to segment the customer base without the use of complex models or additional data requirements. Since all that is required is a purchase history, various applications become possible. For example, in keeping with the current emphasis on category management, scanner panel data can be used to track purchase histories of a household within a category, and clusters determined with the pattern-based segmentation technique. This allows for an accurate clustering strategy with a specific category focus, resulting in well-targeted implementation strategies.

The simplicity of pattern-based segmentation may come at the cost of some finer segmentation issues, but depending on the purpose of the analysis, it may well be worth it.

\section{Acknowledgments}

This project was funded in part by a research grant from the School of Management, State University of New York at Buffalo.

\section{References}

1 Mcalister, L. and Edgar, P. (1982) 'Variety seeking behavior: An interdisciplinary review', Journal of Consumer Research, Vol. 9 , No. 3, p. 311.

2 Givon, M. (1984) 'Variety seeking through brand switching', Marketing Science, Vol. 3, No. 1, p. 1.

3 Lattin, J. M. and Leigh, M. (1985) 'Using a variety-seeking model to identify substitute and complementary relationships among competing products', Journal of Marketing Research, Vol. 22, No. 003, p. 330.

4 Lattin, J. M. (1987) 'A model of balanced choice behavior', Marketing Science, Vol. 6, No. 1, p. 48.

5 Bawa, K. (1990) 'Modeling inertia and variety seeking tendencies in brand choice behavior', Marketing Science, Vol. 9, No. 3, p. 263.

6 Trivedi, M., Bass, F. M. and Rao, R. C. (1994) 'A model of stochastic variety-seeking', Marketing Science, Vol. 13, No. 3, pp. 27424 pages.

7 Feinberg, F. M., Kahn, B. E. and Mcalister, L. (1992) 'Market share response when consumers seek variety', Journal of Marketing Research, Vol. 29, No. 2, p. 227.

8 Kahn, B. E. and Louie, T. A. (1990) 'Effects of retraction of price promotions on brand choice behavior for variety-seeking and last-purchase-loyal consumers', Journal of Marketing Research, Vol. 27, No. 3, p. 279.

9 Kahn, B. E. and Raju, J. S. (1991) 'Effects of price promotions on variety-seeking and reinforcement behavior', Marketing Science, Vol. 10, No. 4, p. 316.

10 Trivedi, M. (1999) 'Using variety-seeking-based segmentation to study promotional response', Journal of Academy of Marketing Science, Vol. 27, No. 1, pp. 37-49.

11 Trivedi, M. and Morgan, M. S. (1996) 'Brand-specific heterogeneity and market-level brand switching', The Journal of Product and Brand Management, Vol. 5, No. 1, p. 29.

12 Trivedi, M. and Morgan, M. S. (2003) 'Promotional evaluation and response among variety seeking segments. Executive summary', The Journal of Product and Brand Management, Vol. 12, No. 6/7, pp. 408-425.

13 Morgan, M. S. and Trivedi, M. (1996) 'Inferring the order of the choice process using consumer purchase histories', Journal of Business \& Economic Statistics, Vol. 14, No. 2, p. 221.

14 Hassan, S. S., Craft, S. and Kortam, W. (2005) 'Understanding the new bases for global market segmentation', The Journal of Consumer Marketing, Vol. 20, No. 4/5, pp. 446-462.

15 Rundle-Thiele, S. and Bennett, R. (2001) 'A brand for all seasons? A discussion of brand loyalty approaches and their applicability for different markets', The Journal of Product and Brand Management, Vol. 10, No. 1, pp. 25-37. 